\title{
109. Syntheses of Azulene and 1-Azaazulanone Derivatives by the Application of Cyanoacetamide to Tropolone and 4-Methyltropolone Methyl Ethers ${ }^{1)}$
}

\author{
By Tetsuo Nozoe, Shûichi SETo, and Shigeo Nozoe \\ Chemical Institute, Faculty of Science, Tôhoku University, Sendai, Japan \\ (Comm. by K. Gото, м.J.A., July 12, 1956)
}

Various kinds of heterocyclic azulenoid compounds have been synthesized in this Laboratory, starting with troponoid compounds. ${ }^{233}$; More recently, azulene derivatives possessing amino and hydroxyl groups in the 2-position have been obtained by the application of ethyl cyanoacetate or malonic dinitrile to 2-halo- and 2-methoxytropones, in the presence of sodium alkoxide. ${ }^{45)}$

Some time ago, Cook et al. ${ }^{6)}$ applied cyanoacetamide to colchicine, in the presence of sodium ethoxide, and obtained a condensate agreeing with the formula $\mathrm{C}_{24} \mathrm{H}_{24} \mathrm{O}_{5} \mathrm{~N}_{3} \mathrm{Cl}$. At that time, tropolone structure had not been proposed for the colchicine molecule and Cook and others considered this condensate to be a hydrochloride of a complex quinoline derivative. In this connection, it seemed interesting to examine the action of cyanoacetamide on tropolone methyl ethers and 2-halotropones.

Application of two molar equivalents of cyanoacetamide to tropolone methyl ether, in the presence of sodium ethoxide, at room temperature, afforded in approx. 20\% yield, a very sparingly soluble orange crystals (Ia) with m.p. 262-263 (Anal. Caled. for $\mathrm{C}_{12} \mathrm{H}_{11} \mathrm{O}_{2} \mathrm{~N}_{3}$ : C, 62.87; $\mathrm{H}, 4.84 ; \mathrm{N}, 18.33$. Found: C, 63.28; H, 4.55; N, 18.09), and in about $60 \%$ yield, yellow needle crystals (IIa), m.p. $305^{\circ}$ (decomp.) (Anal. Calcd. for $\mathrm{C}_{10} \mathrm{H}_{6} \mathrm{ON}_{2}$ : C, 70.58; $\mathrm{H}, 3.55 ; \mathrm{N}, 16.46$. Found: $\mathrm{C}, 70.45$; $\mathrm{H}, 3.67 ; \mathrm{N}, 16.55$ ). The ultraviolet spectra of (Ia) and (IIa) are extremely similar respectively to those of 2-amino-1,3-diethoxycarbonylazulene $^{4)}(\mathrm{Ib})$ and 3-ethoxycarbonyl-2-oxo-1,2-dihydro-1-azaazulene (3ethoxycarbonyl-1-azaazulan-2-one) ${ }^{4)}$ (IIb) (cf. Fig. 1, Fig. 2). Their infrared spectrum revealed the presence of an $\mathrm{NH}_{2}$ group $\left(3400 \mathrm{~cm}^{-1}\right)$ in (Ia) and a $\mathrm{CN}$ group $\left(2200 \mathrm{~cm}^{-1}\right)$ in (IIa).

From the foregoing results, (Ia) was found to be 2-amino-1,3dicarboxamide-azulene and (IIa), 3-cyano-2-oxo-1,2-dihydro-1-azaazulene (3-cyano-1-azaazulan-2-one).

Heating of (IIa) with phosphoryl chloride in a sealed tube affords yellow needles (III), m.p. $230^{\circ}$ (Anal. Calcd. for $\mathrm{C}_{10} \mathrm{H}_{5} \mathrm{~N}_{2} \mathrm{Cl}$ : C, 63.63; H, 2.64; N, 15.38. Found: C, 63.88; H, 2.55; N, 15.40). Its ultraviolet spectrum is given in Fig. 3. 


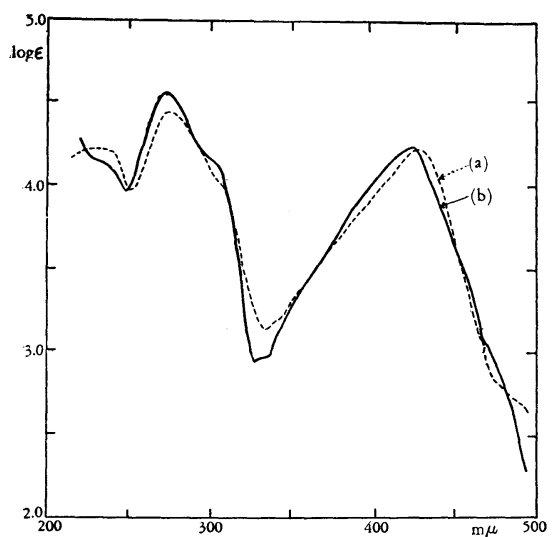

Fig. 1 Ultraviolet absorption spectra in methanol
a) 3-Ethoxycarbonyl-1-azaazulan- 2-one (IIb)
b) 3-Cyano-1-azaazulan-2-one (IIa)

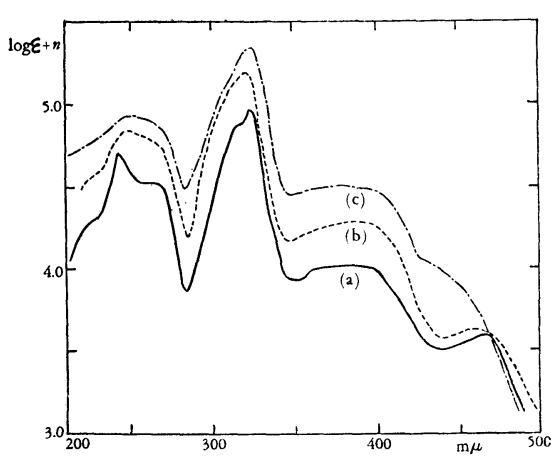

Fig. 2. Ultraviolet absorption spectra in methanol

a) 2-Amino-1,3-diethoxycarbonylazulene (Ia) $(\log \varepsilon+0)$

b) 2-Amino-1,3-dicarboxamideazulene $(\mathrm{Ib})(\log \varepsilon+0.2)$

c) 2-Amino-1,3-dicarboxamide-5methylazulene (V) $(\log \varepsilon+0.4)$

On the other hand, application of ammonia to 3-ethoxycarbonyl1-azaazulan-2-one (IIb), ${ }^{4}$ obtained from 2-aminotropone and diethyl malonate, to form the amide (IIc), m.p. 295-300 (decomp.) (Anal. Calcd. for $\mathrm{C}_{10} \mathrm{H}_{8} \mathrm{O}_{2} \mathrm{~N}_{2}: \mathrm{C}, 63.82 ; \mathrm{H}, 4.29 ; \mathrm{N}, 14.89$. Found: C, 64.00; $\mathrm{H}, 4.02 ; \mathrm{N}, 14.78$ ), and its reaction with phosphoryl chloride affords a substance m.p. $229-230^{\circ}$, identical with the foregoing (III). This indicates that (III) is 2-chloro-3-cyano-1-azaazulene.

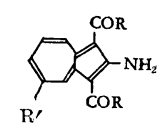

(I)

(Ia): $\quad \mathbf{R}=\mathrm{NH}_{2}, \mathbf{R}^{\prime}=\mathrm{H}$

(Ib): $\quad \mathbf{R}=\mathrm{OC}_{2} \mathrm{H}_{5}, \mathrm{R}^{\prime}=\mathrm{H}$

(V): $\quad \mathbf{R}=\mathrm{NH}_{2}, \mathbf{R}^{\prime}=\mathrm{CH}_{3}$

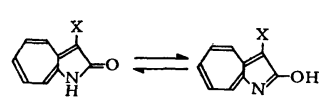

(II)

(IIa): $\quad \mathrm{X}=\mathrm{CN}$

(IIb): $\quad \mathrm{X}=\mathrm{COOC}_{2} \mathrm{H}_{5}$

(IIc): $\mathrm{X}=\mathrm{CONH}_{2}$

It is interesting to note that the application of cyanoacetamide at room temperature to tropolone methyl ether affords both 2-aminoazulene and 1-azaazulanone derivatives in a good yield. In order to consider such reaction mechanism, it is necessary to know to which the active methylene group of the cyanoacetamide molecule bonds as a carbanion, with the carbonyl carbon $\left(\mathrm{C}_{1}\right)$ or the carbon $\left(\mathrm{C}_{2}\right)$ at which the methoxyl is attached in the tropolone methyl ether. As a means of elucidating this problem, application of cyanoacetamide to the two isomeric ethers ${ }^{7}$ (IVa and IVb) of 4-methyltropolone, in the presence of sodium ethoxide was attempted.

This reaction afforded, from (IVa), a small amount of sparingly 
soluble orange crystals (V), m.p. 287-290 (Anal. Calcd. for $\mathrm{C}_{13} \mathrm{H}_{13} \mathrm{O}_{2} \mathrm{~N}_{3}$ : $\mathrm{N}, 17.28$. Found: $\mathrm{N}, 17.41$ ), and a chief product as yellow needles (VIa), m.p. $318^{\circ}$ (decomp.), $\lambda_{\max }^{\mathrm{MeOH}} 274 \mathrm{~m} \mu \quad(\log \varepsilon=4.600), 425$ (4.311) (Anal. Caled. for $\mathrm{C}_{11} \mathrm{H}_{8} \mathrm{ON}_{2}$ : C, 71.72; H, 4.38; N, 15.21. Found: C, $71.55 ; \mathrm{H}, 4.51 ; \mathrm{N}, 15.10)$. The other isomer (IVb) also afforded a small amount of $(\mathrm{V})$ and yellow needles (VIb), m.p. $260^{\circ}$ (decomp.), $\lambda_{\max }^{\mathrm{MeOH}} 277 \mathrm{~m} \mu \quad(\log \varepsilon=4.574), 419$ (4.199) (Anal. Found: C, 71.92; H, 4.12; N, 15.18). From the results of analysis and its ultraviolet spectra (cf. Fig. 2), (V) was found to be 2-amino-1,3-dicarboxamide5 -methylazulene.

Heating of (VIa) and (VIb) each with phosphoryl chloride in a sealed tube respectively afforded yellow needles (VIIa), m.p. $224^{\circ}$, $\lambda_{\max }^{\mathrm{MeOH}} 281 \mathrm{~m} \mu(\log \varepsilon=4.714), 325$ (3.909), 445 (3.020) (Anal. Caled. for $\mathrm{C}_{11} \mathrm{H}_{7} \mathrm{~N}_{2} \mathrm{Cl}:$ C, 65.19; H, 3.48; N, 13.85. Found: C, 65.08; H, 3.29; $\mathrm{N}, 14.00)$ and yellow scaly crystals (VIIb), m.p. 203-204 ${ }^{\circ}, \lambda_{\max }^{\mathrm{Meor}}$ $286 \mathrm{~m} \mu(\log \varepsilon=4.801), 325$ (3.879), 445 (3.191) (Anal. Found: C, 65.21; $\mathrm{H}, 3.36 ; \mathrm{N}, 13.91$ ). Since both (VIIa) and (VIIb) exhibited ultraviolet spectrum similar to that of the foregoing (III) (cf. Fig. 3), it seems certain that they are isomeric 2-chloro-3-cyano-azaazulene homologs

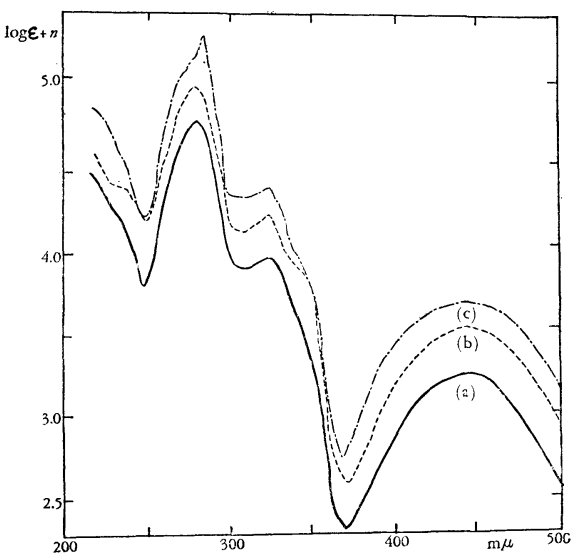

Fig. 3. Ultraviolet absorption spectra in methanol

a) 2-Chloro-3-cyano-1-azaazulene (III) $(\log \varepsilon+0)$

b) 2-Chloro-3-cyano-7-methyl-1azaazulene (VIIa) $(\log \varepsilon+0.2)$

c) 2-Chloro-3-cyano-5-methyl-1azaazulene (VIIb) $(\log \varepsilon+0.4)$ with a methyl group in the 5-position in one and 7-position in the other.

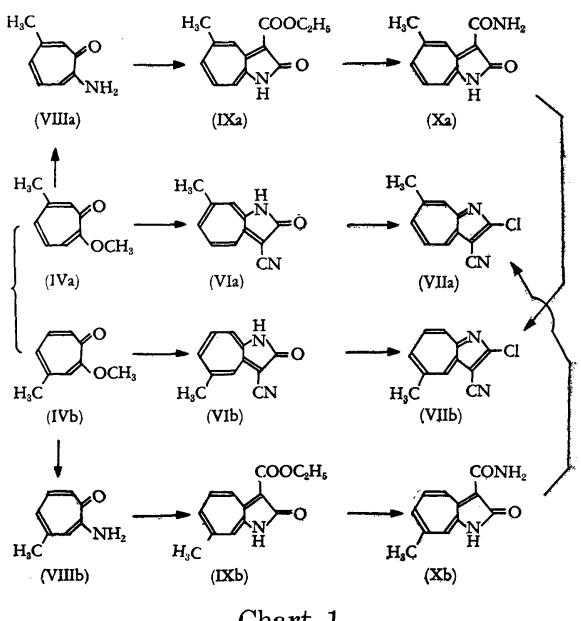

Chart 1

In order to clarify the position of this methyl group, these two substances were synthesized from the compounds in which the relative position of the nitrogen in the 1-azaazulene ring and of the methyl group in the side chain was unequivocal (Chart 1).

Diethyl malonate was applied, in the presence of sodium ethoxide, 
to the two isomeric 2-amino-4 (and 6)-methyltropones (VIIIa) and (VIIIb), derived separately and respectively from (IVa) and (IVb), and the products obtained from each were 3-ethoxycarbonyl-5-methyl-1-azaazulan2-one (IXa) as yellow microneedles, m.p. 208-209 ${ }^{\circ}, \lambda_{\max }^{\mathrm{MeOH}} 278 \mathrm{~m} \mu$ ( $\log \varepsilon$ =4.516), 420 (4.199) (Anal. Calcd. for $\mathrm{C}_{13} \mathrm{H}_{13} \mathrm{O}_{3} \mathrm{~N}$ : C, 67.52; H, 5.67; $\mathrm{N}, 6.06$. Found: C, 67.69; H, 5.40; N, 6.12), from (VIIIa), and 3ethoxycarbonyl-7-methyl-1-azaazulan-2-one (IXb) as yellow needles, m.p. 244-245 ${ }^{\circ} \lambda_{\max }^{\mathrm{MeOH}} 275 \mathrm{~m} \mu(\log \varepsilon=4.45), 427$ (4.22) (Anal. Found: C, 67.23; $\mathrm{H}, 5.57 ; \mathrm{N}, 6.25$ ), from (VIIIb).

Treatment of the acid amide (Xa) of yellow needles, m.p. 276$280^{\circ}$, obtained from (IXa), and that (Xb) of m.p. over $300^{\circ}$ obtained from (IXb), each with phosphoryl chloride afforded the foregoing (VIIb) from (Xa), and (VIIa) from (Xb) respectively.

This shows that in this reaction, the carbanion derived from cyanoacetamide attacks the $\mathrm{C}_{2}$ with a methoxyl group in the tropolone ring and successive dehydrative cyclization between the carbonyl and the amino group in the intermediate thereby formed results in the formation of an azaazulene derivative (Chart 2).

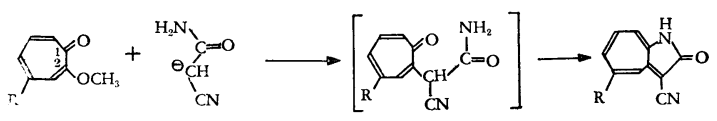

Chart 2

From the results of these experiments, afore-mentioned condensate obtained by Cook et al. in the reaction of colchicine and cyanoace-

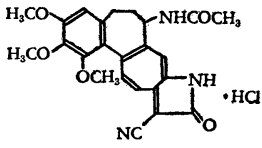

(XI) tamide, is assumed to be following structure (XI).

Details of the present study and the reaction of cyanoacetamide with 2-halotropones and colchicine will be reported in the near future. A part of the expenses for this study was defrayed by a Grant

in Aid of Scientific Research from the Ministry of Education which is herewith gratefully acknowledged.

\section{References}

1) Paper read before the Tôhoku Local Meeting of the Chemical Society of Japan, May 14, 1956.

2) T. Nozoe: Chem. and Chem. Ind. (Japan), 7, 413 (1954).

3) T. Nozoe: Progr. Chem. Org. Nat. Prod. (Zechmeister), 13, 232, Springer Verlag, Wien (1956).

4) T. Nozoe, S. Matsumura, Y. Murase, and S. Seto: Chem. \& Ind., 1955, 1257.

5) T. Nozoe, S. Seto, S. Matsumura, and T. Asano: Proc. Japan Acad., 32, 339 (1956).

6) J. W. Cook, W. Graham, A. Cohen, R. W. Lapsley, and C. A. Lawrence: J. Chem. Soc., 1944, 322 .

7) P. Akroyd, R. D. Haworth, and J. D. Hobson: Ibid., 1951, 3427. 